\title{
Berlin'deki Türk Restoranlarını Ziyaret Eden Almanların Demografik Özelliklerine Göre Destinasyonu Ziyaret Etme Niyetlerinin Değerlendirilmesi ${ }^{1}$
}

\author{
DOI: $10.26466 /$ opus.555643
}

\section{Sami Sonat Özdemir* - Düriye Bozok**}

*Arş Gör.Dr., Balıkesir Üni., Turizm Fak., Gastronomi ve Mutfak San. Böl., Balıkesir/Türkiye E-Posta: ssonatozdemir@balikesir.edu.tr ORCID: $\quad$ 0000-0003-4796-6083

**Prof. Dr., Balıkesir Üni., Turizm Fak., Gastronomi ve Mutfak San. Böl., Balıkesir/Türkiye E-Posta: dbozok@balikesir.edu.tr

ORCID: $\quad \underline{0000-0002-3703-6918}$

\section{Öz}

Etnik ve yöresel mutfağa ait unsurlar, turistlerin bir destinasyonu ziyaret etme davranışı geliştirmelerinde temel çekiciliklerden biri olarak ön plana çıkmaktadır. Söz konusuçekicilik unsurları olarak yöresel yiyecekleri ait olduğu destinasyona gitmeden deneyimlemenin turistlerde destinasyonu ziyaret niyeti oluşturup oluşturmadığının tespiti, bu çalışmanın temel amacın oluşturmaktadır. Bu kapsamda, Berlin'de faaliyet gösteren Türk restoranlarını ziyaret eden Almanlar çalışmanın evreni olarak belirlenmiştir. Bu kapsamda çalışmaya katılanların demografik özellikleri ortaya konulmuş ve bu özelliklerin Türkiye'yi ziyaret etme niyetlerini ne şekilde farklılaştırdığı analiz edilmeye çalışılmıştır. Elde edilen sonuçlar, yaş, cinsiyet, Türkiye'yi daha önce ziyaret etmiş olma ve kalış süreleri değişkenlerinin, çalışmaya katılan Almanların Türkiye'yi ziyaret etme niyetleri üzerinde farklılık yarattı̆̆ıı ortaya koymaktadır. Bu sonuçlara göre, Türkiye'yi daha önce ziyaret etmeyen katılımcilar, Türk restoranların deneyimlemesinin ardından daha yüksek bir oranda Türkiye' ye ziyaret niyeti geliştirmektedir. Bununla birlikte, Türkiye'yi hâlihazırda ziyaret etmiş olan katılımcılar ile bu ziyaretlerin süresi 10 gece ve üzeri olan katılımcıların ziyaret niyetlerinin düşük olduğu ortaya çıkmaktadır.

Anahtar Kelimeler: Demografik Özellikler, Ziyaret Niyeti, Türk Restoranları, Berlin.

\footnotetext{
${ }^{1}$ Bu çalışma birinci yazarın ikinci yazar danışmanlığında hazırladığı doktora tezi kapsamında üretilmiştir
} 


\title{
Evaluation of The Intention to Visit The Destination According to Demographic Characteristics of Germans Visiting Turkish Restaurants in Berlin
}

\begin{abstract}
The elements of ethnic and regional cuisine come to the forefront as one of the main attractions for tourists to develop visiting intention to a destination. The main purpose of this study is to determine whether or not the local food experience intends tourists visit a destination, by having the regional food out of the destination. In this context, the Germans who visited Turkish restaurants in Berlin were identified as the universe of the study. In this context, the effects of demographic features that differentiate the visiting intention of tourists analyzed. Due to the obtained results, age, gender, previous visits and duration of visits create differences on Germans who participated in the study over the intention of visiting Turkey. According to these results, participants who have not visited Turkey before, developing a higher rate of intention to visit Turkey after experiencing Turkish restaurants in Berlin. However, the participants that have visited Turkey before and stay 10 nights and more, develop lower level intentions to visit Turkey.
\end{abstract}

Keywords: Demographic Characteristics, Visiting Intention, Turkish Restaurants, Berlin. 


\section{Giriş}

Günümüz turistlerinin bilgiye daha kolay ulaşabilir yapıda, gezgin ve macera sever olarak nitelendirilebiliyor olması, davranışsal niyetlerinin giderek daha fazla faktörden etkileniyor olduğunu açıklamaktadır. Bahsi geçen özelliklere sahip turistlerin, destinasyonu ziyaret etme niyetlerinin arkasında, bir çok motivasyon faktörü yer almaktadır (Chayanti, 2014). Tutum ile birlikte, destinasyon imajı, davranışlar, popüler kültür ürünleri, yerel ürünler, genel imaj, sosyo-kültürel özellikler, yenilik arayışı, yiyecek ve benzeri faktörlerin ziyaret etme niyetini olumlu açılardan etkilediği, alan yazında yer alan birçok araştırma kapsamında ortaya koyulmuştur. Bütün bu faktörlere ek olarak, demografik unsurlar da, ziyaret niyetini etkileyen unsurlardan biri olarak önem arz etmektedir.

Bu çalışma, Berlin'deki Türk restoranlarını ziyaret eden Almanların, Türkiye'yi ziyaret niyetlerinin demografik özelliklerine göre farklılık gösterip göstermediğinin ortaya koyulması amacıyla, 2016-2018 yılları arasında toplanan verilerin SPSS 21.0 veri analiz programı ile analiz edilmesi ve sonuçların değerlendirilmesiyle hazırlanmıştır. Çalışma, Türkiye turizm talebinde önemli pay sahibi olan Almanlara yönelik bulguları içermesi ve söz konusu bulguların sektörel plan ve stratejilerin oluşturulmasına katkı sağlama potansiyeli bağlamında önemlidir.

\section{Destinasyonu Ziyaret Etme Niyeti ve Bu Niyeti Etkileyen Faktörler}

Yeme-içme unsurlarının destinasyonu ziyaret etme niyetine yönelik etkisini araştıran çalışmalar ilgili literatürde sıklıkla temsil edilen araştırma alanları arasındadır. Özellikle turistler tarafından daha önce ziyaret edilen ve ziyaret esnasında yerel yeme-içme unsurlarının deneyimlendiği destinasyonlara yönelik tekrar ziyaret niyetinin güçlü olduğu ortaya çıkmaktadir.

Yöresel veya etnik yeme-içme unsurlarının deneyimlenmesinin tekrar ziyaret üzerine etkisini ortaya koyan çalışmalarında, Kivela ve Crotts (2006), Hong Kong şehrini ziyaret eden turistlerin tekrar ziyaret davranışları üzerinde gastronomi ile ilgili öğelerin etkilerini analiz etmişler, söz konusu unsurların ziyaretçi deneyiminin ayrılmaz bir parçası olduğunu ortaya koymuşlardır. Barros ve Assaf (2012) da, turistlerin Lizbon şehrini 
tekrar ziyaret etme niyetini etkileyen başlica faktörleri belirlemeye yönelik gerçekleştirdikleri çalışmalarında, gece hayatı, hava durumu, güvenlik ve etkinlikler gibi faktörlerin ötesinde yiyecek kalitesinin de ziyaret etme niyeti üzerinde önemli ve pozitif rol oynadığı sonucuna varmışlardır.

Alderighi vd. (2014) ise yerel yiyecek özeliklerinin turizm destinasyonlarının çekiciliklerine etkisini araştırmışlardır. Çalışmalarında, tüketicilerin İtalya'nın kuzeyinde üç dağ rezidansını tekrar ziyaret etme niyetlerine, bu yerlerde bilinen beş yerel yiyecek ürününün (pizzoccheri makarna, Bresaola kurutulmuş sığırı, Fontina peyniri, Melinda elmaları, Speck füme jambon) etkisini araştırmışlardır. 1100 İtalyan denek üzerinde gerçekleştirilen araştırma bulgularına göre, yerel yiyeceklerin, tekrar ziyaret niyeti üzerinde olumlu bir etkisi vardır.

Gastronomi turizmi amacıyla gerçekleştirilen ziyaretler başta olmak üzere, ilk kez ziyaret edilecek destinasyonlara yönelik ziyaret niyetlerinin ortaya koyulduğu çalışmalardan elde edilen sonuçlar önem arz etmektedir. Philips vd. (2013), Kore yemekleri hakkında bilgi sahibi olan kişilerin, yemekleri deneyimleme amaciyla, Güney Kore'yi ziyaret etme niyetlerinin araştırılmasına yönelik çalışmalarında, bir ülkeyi ziyaret etme niyetinin belirlenmesinde, yerel yiyecek tüketme niyetinin etkili olabileceğini belirtmişlerdir. Chayanti vd. (2014) de, tüketicilerin yeni yiyecekleri deneyimleme arayışının, bir destinasyonu ziyaret etme niyetini artırmak için birincil itici motivasyon faktörlerinden biri olabileceğini belirtmişlerdir. Buna göre, tüketicinin sahip olduğu ürün bilgisi yüksek ve yiyecekler pozitif bir imaja sahip olduğunda, destinasyonu ziyaret etme ve ürünü deneyimlemeye yönelik olumlu bir tutum oluşabilmektedir. Spark vd. (2003), şarap turizmi bölgelerini rekreasyonel amaçlı olarak ziyaret etme niyetini etkileyen faktörleri, Ajzen (1991)'in planlanmış davranış teorisini kullanarak incelemiştir. Çalışmanın sonucunda, geçmiş deneyimleri koruma davranışı (bireyin geçmiş deneyimlerindeki performansını olumlu veya olumsuz olarak değerlendirmesi) ve algılanan davranış kontrolünün (belirli bir davranışın uygulanmasının kolaylığı veya zorluğu) ziyaret etme niyeti üzerinde doğrudan etkisi olduğunu ortaya koymuşlardır.

İlgili çalışmalar göstermektedir ki, yerel yiyecek tüketme niyeti, yiyecek imajı, mutfak bilinirliği, destinasyonu ziyaret etme niyeti üzerinde etkili olmaktadır. İlgili faktörlerden bağımsız olarak demografik faktörler, 
tüketici davranışlarının her aşamasında olduğu gibi ziyaret niyeti oluşturulmasında da oldukça önemli unsurlar olarak bu çalışmada ele alınmıştir.

\section{Yöntem}

\section{Evren ve Örneklem}

Çalışmanın evrenini Berlin'de faaliyet gösteren Türk restoranlarını ziyaret eden Almanlar oluşturmaktadır. 2016-2018 yılları arasında Berlin'de Türk restoranlarını ziyaret eden 271 kişiye kolayda örnekleme yöntemiyle ulaşılmış ve araştırma kapsamında kullanılan anketi doldurmaları sağlanmıştır.

\section{Veri Toplama Araci}

Araştırma kapsamında hedeflenen amaçlara ulaşılması için gerekli olan verilerin toplanması aşamasında, Horng vd (2012) tarafından geliştirilen, geçerlilik ve güvenilirliği kanıtlanmış ziyaret niyeti ölçeği kullanılmıştır. İlgili ölçek Tablo 1'de gösterilmiştir.

Tablo 1. Araştırmada Kullanılan Ziyaret Niyeti Ölçeği, (Horng vd., 2012)

\begin{tabular}{l}
\hline Ziyaret Niyeti \\
\hline Gelecek yıl Türkiye'yi ziyaret edebilirim. \\
Gelecek yıl Türkiye'yi ziyaret etmeyi planlıyorum. \\
Türkiye'yi ziyaret etmek istiyorum. \\
\hline
\end{tabular}

\section{Verilerin Analizi}

Araştırmadan elde edilen veriler, "SPSS 21.0 for Windows" veri analiz programında analiz edilmiştir. Araştırmada frekans analizinin ardından, verilerin normal dağılım göstermesiyle, parametrik testlerden gruplar arası farklılıkları ortaya koymaya yönelik T Testi ve Anova (varyans analizi) testleri gerçekleştirilmiştir. 


\section{Bulgular}

Bu bölümde, Berlin'deki Türk restoranlarını ziyaret eden Almanların demografik özelliklerinin, Türkiye'yi ziyaret niyetlerine etkisini ortaya koymaya yönelik olarak toplanan veriler analiz edilerek elde edilen bulguların yorumlanması sağlanacaktır.

Çalışmaya katılanların demografik özellikleri Tablo 2'de yer almaktadır.

Tablo 2. Katılımcıların Demografik Özellikleri

\begin{tabular}{|c|c|c|}
\hline & Say1 & Yüzde(\%) \\
\hline Cinsiyet & 271 & 100 \\
\hline Kadın & 100 & 36,9 \\
\hline Erkek & 171 & 63,1 \\
\hline Yaş & 271 & 100 \\
\hline 20'den küçük & 36 & 13,3 \\
\hline $20-29$ & 84 & 31,0 \\
\hline $30-39$ & 71 & 26,2 \\
\hline $40-49$ & 59 & 21,8 \\
\hline $50-59$ & 21 & 7,7 \\
\hline Türkiye'yi Ziyaret & 271 & 100 \\
\hline Hayır & 98 & 36,2 \\
\hline Evet, 1 kez & 67 & 24,7 \\
\hline Evet, 2 kez & 45 & 16,6 \\
\hline Evet, 3 kez & 21 & 7,7 \\
\hline Evet, 4 kez ve daha fazla & 40 & 14,8 \\
\hline Türkiye'de Kalış Süresi & 271 & 100 \\
\hline 1 gece & 11 & 4,1 \\
\hline 2-3 gece & 22 & 8,1 \\
\hline 4-5 gece & 67 & 24,7 \\
\hline 6-7 gece & 84 & 31,0 \\
\hline $8-9$ gece & 47 & 17,3 \\
\hline 10 gece ve daha fazla & 40 & 14,8 \\
\hline Türk Restoranlarını Ziyaret Sıklı̆̆ı & 271 & 100 \\
\hline Ayda 1 kez ya da hiç & 124 & 45,8 \\
\hline Ayda 2 kez & 76 & 28,0 \\
\hline Ayda 3 kez & 22 & 8,1 \\
\hline Ayda 4 kez ve daha fazla & 49 & 18,1 \\
\hline Diğer Etnik Restoranları Ziyaret & 271 & 100 \\
\hline Hayır & 61 & 22,5 \\
\hline Evet, Türk restoranlarından daha az & 98 & 36,2 \\
\hline Evet, Türk restoranlarından daha çok & 112 & 41,3 \\
\hline
\end{tabular}


Katılımcıların demografik özellikleri dikkate alındığında, çalışmaya katılan erkeklerin kadınlardan yaklaşık \%27 oranında daha fazla sayıda olduğu görülmektedir. Katılımcıların \%60'a yakını 29 yaşından küçüktür ve aynı oranda Türkiye'yi ya hiç ziyaret etmemişler ya da yalnızca $1 \mathrm{kez}$ ziyaret etmişlerdir. Türkiye'yi daha önce ziyaret eden katılımcılar, \%55 oranında 4 ve 7 gece arasında konaklama gerçekleştirmişlerdir. Çalışmaya katılanlar, yaşadıkları yerdeki Türk restoranlarını \%45 oranında ayda 1 kez ziyaret etmekte ya da etmemektedir. Bununla birlikte katılımcılar, Türk restoranları dışında kalan etnik restoranları \%41 ile Türk restoranlarından daha sık ziyaret etmektedirler. Çalışma kapsamında gerçekleştirilen ikinci analiz katılımcıların cinsiyet özelliklerinin ziyaret etme niyetlerini farklılaştırıp farklılaştırmadığının ortaya çıkarılması için yapılan T Testi analizidir. İlgili analiz Tablo 3'de yer almaktadır.

Tablo 3. Cinsiyet Değişkenine Göre Destinasyonu Ziyaret Niyeti Analizi

\begin{tabular}{lllllc}
\hline & F & Sig. & \multicolumn{1}{c}{$\mathbf{t}$} & df & $\begin{array}{l}\text { Sig. } \\
\text { (2-tailed) }\end{array}$ \\
\hline & Lower & Upper & Lower & Upper & Lowerr \\
\hline Equal variances assumed & 10,142 &, 002 & $-3,100$ & 266 &, 002 \\
Equal variances not assumed & & & $-3,322$ & 241,227 &, 001 \\
\hline
\end{tabular}

Tablo 3'den elde edilen bulgulara göre $\mathrm{p}<0,05$ anlamlılık düzeyinde, Berlin'de faaliyet gösteren Türk restoranlarını ziyaret eden kadın ve erkeklerin Türkiye'yi ziyaret niyetleri arasında anlamlı bir farkın ortaya çıtığı görülmektedir.

Çalışmaya katılan Almanların yaş gruplarına göre, Türkiye'yi ziyaret niyetlerinin ne şekilde ortaya çıtığının belirlenmesi amacıyla gerçekleştirilen "Varyans Analizi" sonucuna göre, yaş ile ziyaret niyeti arasında anlamlı farklılık bulunmaktadır. İlgili analiz Tablo 4'de yer almaktadır.

Tablo 4. Yaş Değişkenine Göre Destinasyonu Ziyaret Etme Niyeti Analizi

\begin{tabular}{lllcll}
\hline & Sum of Squares & df & Mean Square & F & Sig. \\
\hline Between Groups & 37,213 & 4 & 9,303 & 8,710 &, 000 \\
Within Groups & 284,125 & 266 & 1,068 & & \\
Total & 321,338 & 270 & & & \\
\hline
\end{tabular}

Tablo 4'de yer alan ve gruplar arası farklılıkların var olduğunu gösteren bulgu neticesinde, farklılıkların hangi gruptan kaynaklandığının 
ve farklılıkların yönünün belirlenebilmesi amaciyla "Post-Hoc" testleri gerçekleştirilmiştir. Tablo 5 "Scheffe" testi sonucuna göre, hangi gruplar arasında destinasyonu ziyaret etme niyeti bağlamında anlamlı farklar bulunduğunu hangi yaş gruplarının ziyaret niyetinin daha güçlü olduğunu ortaya koyan bulguları içermektedir.

Tablo 5. Yaş Değişkenine Göre Destinasyonu Ziyaret Niyetine İlişkin Farklılıkların Analizi

\begin{tabular}{lllll}
\hline 20'den küçük & $20-29$ &,- 48942 &, 20588 &, 230 \\
& $30-39$ &,$- 65636\left(^{*}\right)$ &, 21146 &, 050 \\
& $40-49$ &, 17247 &, 21857 &, 960 \\
& $50-59$ &, 36376 &, 28379 &, 801 \\
\hline $\mathbf{2 0 - 2 9}$ & 20 'den küçük &, 48942 &, 20588 &, 230 \\
& $30-39$ &,- 16695 &, 16661 &, 909 \\
& $40-49$ &, $66189\left(^{*}\right)$ &, 17556 &, 008 \\
& $50-59$ &, $85317\left(^{*}\right)$ &, 25215 &, 024 \\
\hline $\mathbf{3 0 - 3 9}$ & 20 'den küçük &, $65636\left(^{*}\right)$ &, 21146 &, 050 \\
& $20-29$ &, 16695 &, 16661 &, 909 \\
& $40-49$ &, $82884\left(^{*}\right)$ &, 18207 &, 000 \\
& $50-59$ & $1,02012\left(^{*}\right)$ &, 25673 &, 004 \\
\hline $\mathbf{4 0 - 4 9}$ & 20 'den küçük &,- 17247 &, 21857 &, 960 \\
& $20-29$ &,$- 66189\left(^{*}\right)$ &, 17556 &, 008 \\
& $30-39$ &,$- 82884\left(^{*}\right)$ &, 18207 &, 000 \\
& $50-59$ &, 19128 &, 26262 &, 970 \\
\hline $\mathbf{5 0 - 5 9}$ & 20 'den küçük &,- 36376 &, 28379 &, 801 \\
& $20-29$ &,$- 85317\left(^{*}\right)$ &, 25215 &, 024 \\
& $30-39$ & $-1,02012\left(^{*}\right)$ &, 25673 &, 004 \\
& $40-49$ &,- 19128 &, 26262 &, 970 \\
\hline
\end{tabular}

Tablo 5'de yer alan bulgulara göre Türkiye'yi ziyaret niyetleri, genel olarak ilk üç yaş gurubunu ifade eden 39 yaşına kadar olan katılımcılar ile son iki yaş grubunu ifade eden 40-59 yaş aralığında olan katılımcılar arasında farklılaşmaktadır. Bahsi geçen sınıflamalar dikkate alındığında 40-59 yaş aralığındaki grubun destinasyonu ziyaret etme niyetinin, 39 yaşına kadar olan gruba göre olumlu anlamda daha güçlü olduğu ortaya çıkmaktadır.

Çalışmada ele alınan bir diğer analiz ise, katılımcıların Türkiye'ye daha önceki seyahatlerinin, ziyaret etme niyetine etkisinin araştırıldı̆̆ 1 analizdir. Tablo 6'da yer alan bulgular, Türkiye'ye önceki seyahatlerin ziyaret niyetini farklılaştırdığını ortaya koymuştur. 
Berlin'deki Türk Restoranlarını Ziyaret Eden Almanların Demografik Özelliklerine Göre Destinasyonu Ziyaret Etme NiyetlerininDeğerlendirilmesi

Tablo 6. Daha Önceki Ziyaret Durumuna Göre, Türkiye'yi Ziyaret Etme Niyetinin Analizi

\begin{tabular}{llllll}
\hline & KT & SD & KO & F & p \\
\hline Gruplararas1 & 36,170 & 4 & 9,042 & 8,43 &, 000 \\
Grupiçi & 285,168 & 266 & 1,072 & & \\
Toplam & 321,338 & 270 & & & \\
\hline
\end{tabular}

Tablo 6'da yer alan ve gruplar arası farklılıkların var olduğunu gösteren bulgu neticesinde, farklılıkların hangi gruptan kaynaklandığının ve farklılıkların yönünün belirlenebilmesi amaciyla "Post-Hoc" testleri gerçekleştirilmiştir. Tablo 7 "Scheffe" testi sonucuna göre, Türkiye'yi önceki ziyaret durumuna göre, hangi gruplar arasinda destinasyonu ziyaret etme niyeti bağlamında anlamlı farklar bulunduğunu ortaya koyan bulguları içermektedir.

Tablo 7. Daha Önceki Ziyaret Durumuna Göre, Türkiye'yi Ziyaret Etme Niyetine Yönelik Farklılıkların Analizi

\begin{tabular}{|c|c|c|c|c|}
\hline \multirow[t]{4}{*}{ Hayir } & Evet, bir kez & ,07904 & , 16414 & ,994 \\
\hline & Evet, iki kez & 01459 & 18645 & 1,000 \\
\hline & Evet, üç kez &,- 30499 & 24898 & ,826 \\
\hline & $\begin{array}{l}\text { Evet, dört kez } \\
\text { veya daha fazla }\end{array}$ &,$- 99745\left(^{*}\right)$ & 19427 & ,000 \\
\hline \multirow[t]{4}{*}{ Evet, bir kez } & Hayır &,- 07904 & , 16414 & ,994 \\
\hline & Evet, iki kez &,- 06446 & 19956 & ,999 \\
\hline & Evet, üç kez &,- 38403 & 25894 & 699 \\
\hline & $\begin{array}{l}\text { Evet, dört kez } \\
\text { veya daha fazla }\end{array}$ & $-1,07649\left(^{*}\right)$ & 20689 & ,000 \\
\hline \multirow[t]{4}{*}{ Evet, iki kez } & Hayır &,- 01459 & 18645 & 1,000 \\
\hline & Evet, bir kez & ,06446 & 19956 & ,999 \\
\hline & Evet, üç kez &,- 31958 & ,27363 & 850 \\
\hline & $\begin{array}{l}\text { Evet, dört kez } \\
\text { veya daha fazla }\end{array}$ & $-1,01204\left(^{*}\right)$ & ,22500 & ,001 \\
\hline \multirow[t]{4}{*}{ Evet, üç kez } & Hayır & 30499 & 24898 &, 826 \\
\hline & Evet, bir kez & ,38403 & 25894 & 699 \\
\hline & Evet, iki kez & 31958 & 27363 & 850 \\
\hline & $\begin{array}{l}\text { Evet, dört kez } \\
\text { veya daha fazla }\end{array}$ &,- 69246 & 27902 & 191 \\
\hline \multirow{4}{*}{$\begin{array}{l}\text { Evet, dört kez } \\
\text { veya daha fazla }\end{array}$} & Hayır &, $99745\left(^{*}\right)$ & 19427 & ,000 \\
\hline & Evet, bir kez & $1,07649\left(^{*}\right)$ & 20689 & ,000 \\
\hline & Evet, iki kez & $1,01204\left(^{*}\right)$ & 22500 & ,001 \\
\hline & Evet, üç kez & 69246 & ,27902 & 191 \\
\hline
\end{tabular}


Tablo 7'den elde edilen veriler, daha önce Türkiye'yi ziyaret etmeyenler, 1 kez ziyaret edenler ve 2 kez ziyaret edenler ile 4 veya daha fazla kez ziyaret edenler arasında anlamlı farklılık bulunduğunu ortaya koymaktadır. Buna göre, Türkiye'ye daha önce seyahat gerçekleştirmeyenler veya nispeten daha az seyahat edenler, daha güçlü bir ziyaret niyetine sahiptirler.

Katılımcıların demografik özelliklerinin Türkiye'yi ziyaret niyetlerine etkisine yönelik anlamlı sonuç veren analizlerden bir diğeri ise, önceki ziyaretlerinde Türkiye' de kalış süreleri ile ilişkilidir. İlgili verileri içeren bulgular Tablo 8'de sunulmuştur.

Tablo 8. Önceki Kalış Süresine Göre, Türkiye'yi Ziyaret Niyeti Analizi

\begin{tabular}{llllll}
\hline & KT & SD & KO & F & P \\
\hline Gruplararasi & 17,882 & 4 & 4,471 & 3,529 &, 009 \\
Grupiçi & 216,633 & 171 & 1,267 & & \\
Toplam & 234,515 & 175 & & & \\
\hline
\end{tabular}

Tablo 8'de yer alan ve gruplar arası farklılıkların var olduğunu gösteren bulgu neticesinde, farklılıkların hangi gruptan kaynaklandığının ve farklılıkların yönünün belirlenebilmesi amaciyla "Post-Hoc" testleri gerçekleştirilmiştir. Tablo 9, önceki ziyaret esnasında Türkiye'de kalış sürelerine göre, hangi gruplar arasında destinasyonu ziyaret etme niyeti bağlamında anlamlı farklar bulunduğunu ortaya koyan bulguları içermektedir.

Tablo 9`da yer alan bulgulara göre, katılımcıların önceki Türkiye seyahatlerindeki kalış süreleri 6-7 gece olanlar ile, 10 gece veya daha fazla olanlar ile anlamlı bir farklılık göze çarpmaktadır. Buna göre, 6-7 gece konaklayanlar, 10 gece ve üzeri konaklayanlara göre, daha güçlü bir destinasyonu ziyaret niyetine sahiptirler.

Çalışmada analiz edilen diğer değişkenlerden, katılımcıların Türk restoranlarını ziyaret sıklığı ve diğer etnik restoranları ziyaret durumlarının, Türkiye'ye yönelik ziyaret niyetini etkilediğine yönelik bir bulguya rastlanmamıştır. 
Tablo 9. Önceki Kalış Sürelerine Göre, Türkiye'yi Ziyaret Niyetine Yönelik Farklılıklarn Analizi

\begin{tabular}{lllll}
\hline 1-3 Gece & 4-5 Gece &, 14120 &, 37699 &, 998 \\
& 6-7 Gece &, 25294 &, 37553 &, 978 \\
& 8-9 Gece &,- 10455 &, 42251 & 1,000 \\
10 Gece veya fazla &,- 53618 &, 37553 &, 729 \\
4-5 Gece & 1-3 Gece &,- 14120 &, 37699 &, 998 \\
& 6-7 Gece &, 11174 &, 22980 &, 993 \\
& 8-9 Gece &,- 24574 &, 30050 &, 955 \\
6-7 Gece & 10 Gece veya fazla &,- 67738 &, 22980 &, 074 \\
& 1-3 Gece &,- 25294 &, 37553 &, 978 \\
& 4-5 Gece &,- 11174 &, 22980 &, 993 \\
8-9 Gece & 8-9 Gece &,- 35748 &, 29866 &, 838 \\
& 10 Gece veya fazla &,$- 78912\left(^{*}\right)$ &, 22740 &, 020 \\
& 1-3 Gece &, 10455 &, 42251 & 1,000 \\
& 4-5 Gece &, 24574 &, 30050 &, 955 \\
10 Gece ve fazla & 6-7 Gece &, 35748 &, 29866 &, 838 \\
& 10 Gece veya fazla &,- 43163 &, 29866 &, 720 \\
& 1-3 Gece &, 53618 &, 37553 &, 729 \\
& 4-5 Gece &, 67738 &, 22980 &, 074 \\
& 6-7 Gece &, $78912\left(^{*}\right)$ &, 22740 &, 020 \\
& 8-9 Gece &, 43163 &, 29866 &, 720 \\
\hline
\end{tabular}

\section{Sonuç ve Öneriler}

Berlin'deki Türk restoranlarını ziyaret eden Almanların örneklemini oluşturduğu çalışmada demografik özelliklerin, Türkiye'yi ziyaret etme niyeti üzerindeki etkisi ve bu davranışları ne şekilde farklılaştırdığının tespitine yönelik olarak gerçekleştirilen araştırmada, ulaşılan sonuçlar şu şekildedir.

- Katılımcıların demografik özellikleri, çalışmaya katılanların Almanya'da faaliyet gösteren Türk restoranlarını hiç ziyaret etmediklerini veya yalnızca $1 \mathrm{kez}$ ziyaret ettiklerini göstermektedir. Bununla birlikte bu katılımcıların diğer etnik restoranları Türk restoranlarından daha çok ziyaret ettikleri görülmüştür. Bu durum katılımciların etnik restoran ziyaretinde bulunmaktan ve yerel yiyecekler tüketmekten çekinmediklerini göstermektedir. Türk mutfağına yönelik ziyaretlerin diğer mutfakların temsilcilerinden daha az gerçekleştiriliyor olması, bu durumun sebeplerinin ortaya 
çıkarılmasını gerekli kılmaktadır. Bu konu üzerine gerçekleştirilecek araştırmalar, bu çalışmada elde edilen sonuçların içermediği ve eksik kaldığı noktaları aydınlatacak olması nedeniyle önemlidir.

- Elde edilen bulgular neticesinde, Türk restoranlarını ziyaret edenlerin destinasyonu ziyaret niyetlerinin yaş değişkenine göre farklılık gösterdiğini ortaya koymaktadır. Özellikle 3. yaş olarak adlandırılan guruba dahil olarak değerlendirilebilecek yaş aralığında bulunan katılımcların Türk restoranlarındaki deneyimlerinin, Türkiye'yi ziyaret niyetini güçlendirdiğini göstermektedir. $\mathrm{Bu}$ durum belirtilen yaş grubuna hizmet vermek konusunda uzmanlaşmayı hedefleyen turizm işletmelerine imkanların oluşturulmasında ve geliştirmelerin sağlanması hususunda yol gösterici olabilir. Ayrıca 3. yaş turizminin talep gösterdiği destinasyonlarda sunulan çekiciliklerin, söz konusu grubun seyahatlerinin yoğunlaştırdığ1 dönemler başta olmak üzere, yerel yiyeceklerle ilişkilendirilmesi de katkı sağlayabilecektir.

Türkiye'yi daha önce ziyaret etmeyen katılımcıların, Türk restoranlarını deneyimlemesinin ardından daha yüksek bir oranda Türkiye'ye ziyaret niyeti geliştirdiği görülmektedir. $\mathrm{Bu}$ durum çalışmanın kapsamında ziyaret edilen Türk restoranlarının, Türk mutfağı unsurlarını başarıyla yansitarak ziyaret niyeti oluşturduğunu göstermektedir. Bununla birlikte, Türkiye'yi ziyaretlerinde 10 gece ve üzeri konaklama gerçekleştiren katılımcılar, diğer sürelerde konaklama gerçekleştiren katılımclara göre, daha düşük bir ziyaret niyetine sahip olmaktadırlar. Türkiye'yi hâlihazırda ziyaret etmiş olanlar ile bu ziyaretlerin süresi 10 gece ve üzeri olanların, ziyaret niyetlerinin düşük bir seviyede yer alması nedenleri araştııılması gereken bir durum olarak ortadadır. Bu nedenleri ayrıntılı bir şekilde ortaya koyma amacı taşıyan çalışmaların gerçekleştirilmesi, sorunun çözümüne katkıda bulunabilecektir. 


\title{
EXTENDED ABSTRACT
}

\section{Evaluation Of The Intention To Visit The Destina- tion According To Demographic Characteristics Of Germans Visiting Turkish Restaurants In Berlin}

\author{
Sami Sonat Özdemir - Düriye Bozok \\ Balıkesir University
}

The fact that today's tourists can be more easily accessible to information, as a traveler and adventure lover, explains that their behavioral intentions are increasingly affected by some factors. There are many motivational factors behind the intention of tourists to visit the destination (Chayanti, 2014). It has been demonstrated in the literature that image, behaviors, popular culture products, local products, general image, socio-cultural characteristics, search for novelty, food and similar factors has positively affected the intention to visit the destination. In addition to all these factors, demographic elements are also important as one of the factors affecting the intention to visit.

The elements of ethnic and regional cuisine come to the forefront as one of the main attractions for tourists to develop visiting intention to a destination. The main purpose of this study is to determine whether or not the local food experience intends tourists visit a destination, by having the regional food out of the destination.

Philips et al (2013), found that having knowledge about Korean food could have an positive impact on local food consumption intentions. Chayanti et al (2014) also stated that consumers' search for new foods could be one of the primary driving motivation factors to increase the intention to visit a destination. Accordingly, when the consumer has a high product knowledge and a positive food image, a positive attitude towards visiting the destination and experiencing the product can be developed.

Relevant studies show that the intention to consume local food, the image of the food, the culinary awareness, the intention to visit the destination is effective on the intention to Visit a destination. Regardless of the related factors, demographic factors are considered as important elements in the intention to create a visit as in every stage of consumer behavior. 
The universe of the study consists of Germans visiting Turkish restaurants operating in Berlin. Between 2016-2018, 271 people who visited Turkish restaurants in Berlin were reached with easy sampling method and they were provided to fill the questionnaire.

During the collection of the data needed to achieve the targeted objectives, a visiting intention scale developed by Horng et al. (2012) was used. Data obtained from the study were analyzed in "SPSS 21.0 for Windows" data analysis program. After the frequency analysis, $\mathrm{T}$ test and Anova (variance analysis) tests were conducted to determine the differences between the groups.

Due to the obtained results, age, gender, previous visits and duration of visits create differences on Germans who participated in the study over the intention of visiting Turkey. Considering the demographic characteristics of the participants, it is seen that the men who participated in the study were about $27 \%$ more than the women. Nearly $60 \%$ of the participants were younger than 29 years of age, and at the same rate they did not visit or visited only one time. On the other hand, the frequency of visiting Turkish restaurants and other ethnic restaurants does not affect the intention of visiting. Participants who have not visited Turkey before, developing a higher rate of intention to visit Turkey after experiencing Turkish restaurants in Berlin. However, the participants that have visited Turkey before and stay 10 nights and more, develop lower level intentions to visit Turkey.

The findings, in particular the experience of the Turkish restaurants of older participants, shows that strengthens the intention to visit Turkey. This can be a guideline for the establishment of opportunities for tourism enterprises aiming to specialize in providing service to the mentioned age group and to provide improvements.

Participants, who have not previously visited Turkey, are developing a high proportion intending to visit Turkey after experiencing the Turkish restaurant. This situation shows that the Turkish restaurants visited within the scope of the study successfully reflect the elements of Turkish cuisine and create intention to visit. 


\section{Kaynakça / References}

Ajzen, I. (1991). The theory of planned behavior. Organizational Behavior And Human Decision Processes, 50(2), 179-211.

Alderighi, M., Bianchi, C. ve Lorenzini, E. (2016). The impact of local food specialities on the decision to (re) visit a tourist destination: Market-expanding or business-stealing?. Tourism Management, 57, 323333.

Barros, C. P. ve Assaf, A. G. (2012). Analyzing tourism return intention to an urban destination. Journal Of Hospitality $\mathcal{E}$ Tourism Research, 36(2), 216-231.

Cahyanti, M. M., Rohman, F. ve Irawanto, D. (2014). Investigating the image of Japanese food on intention of behavior: Indonesian intention to visit Japan, Journal of Indonesian Tourism and Development Studies, 2(2), 77-81.

Horng, J. S., Liu, C. H., Chou, H. Y., ve Tsai, C. Y. (2012). Understanding the impact of culinary brand equity and destination familiarity on travel intentions. Tourism management, 33(4), 815-824.

Kivela, J. ve Crotts, J. C. (2006). Tourism and Gastronomy: Gastronomy's influence on how tourists experience a destination. Journal Of Hospitality \& Tourism Research, 30(3), 354-377.

Philips, W. J., Wolfe, K. ve Hodur, N. (2013). Tourist word of mouth and revisit intentions to rural tourism destinations:A case of North Dakota, USA, International Journal of Tourism Research, 15(1), 93-104.

Sparks, B., Wohen, J. ve Klag, S. (2003).Restaurants and the tourist market, International Journal Of Comtemporary Hospitality Management, 15(1), 6-13.

\section{Kaynakça Bilgisi / Citation Information}

Özdemir, S.S. ve Bozok, D. (2019). Berlin'deki Türk restoranlarını ziyaret eden Almanların demografik özelliklerine göre destinasyonu ziyaret etme niyetlerinin değerlendirilmesi. OPUS-Uluslararası Toplum Araştırmaları Dergisi, 11(18), 1310-1324. DOI: 10.26466/opus.555643 